\title{
Pregnancy with pancytopenia: an observational study
}

\section{Sangamesh Mathapati, Aruna Biradar*, Laxmi Sangolli, Gamini B. S., Sridevi H. S.}

Department of Obstetrics and Gynecology, BLDE (DU) Shri B. M. Patil Medical College, Vijayapura, Karnataka, India

Received: 20 June 2020

Accepted: 26 June 2020

\section{*Correspondence:}

Dr. Aruna Biradar,

E-mail: aruna.biradar@bldedu.ac.in

Copyright: () the author(s), publisher and licensee Medip Academy. This is an open-access article distributed under the terms of the Creative Commons Attribution Non-Commercial License, which permits unrestricted non-commercial use, distribution, and reproduction in any medium, provided the original work is properly cited.

\section{ABSTRACT}

Background: Pancytopenia is the reduction in all three major cellular elements of blood; hence it is the simultaneous presence of anaemia, leukopenia and thrombocytopenia. Pancytopenia is associated with many maternal and foetal complications during pregnancy like maternal sepsis, postpartum haemorrhage, pre-eclampsia and preterm labour, IUGR and intrauterine foetal demise.

Methods: The study was conducted at BLDE (Deemed to be) University, Shri B. M. Patil Medical College Hospital and Research Centre. It's an observational study done from November 2019-April 2020. The participants enrolled in the study were subjected for further clinical and laboratory evaluation and followed for feto-maternal outcome.

Results: The incidence of pancytopenia with pregnancy in this study was $3 \%$ and all the patients were vegetarian by diet along with vitamin B12 and folic acid deficiency. They were associated with different maternal and foetal complications.

Conclusions: Proper dietary counselling and well-balanced dietary plans even with plant originate food can prevent the micronutrients deficiency and avoid the deleterious consequences like pancytopenia.

Keywords: Micronutrients, Pancytopenia, Pregnancy

\section{INTRODUCTION}

Pancytopenia is the reduction in all three major cellular elements of blood; hence it is the simultaneous presence of anaemia, leukopenia and thrombocytopenia. ${ }^{1}$ It is a trade which involves bone marrow primarily or secondarily depending on the various pathogenesis. The various etiology of pancytopenia includes aplastic anaemia, megaloblastic anaemia, infections, nutritional deficiencies and malignancies. ${ }^{2}$ Vegetarians are at serious risk of vitamin B12 deficiency an essential micronutrient that plays a specific role in DNA synthesis and in one carbon metabolism.

Vitamin B12 deficiency is common in pregnancy due to increased foetal demand over gestation, an essential micronutrient that plays an important role in nucleic acid synthesis. Deficiency of which leads defective erythropoiesis and neuronal myelinisation. $38 \%$ of women have low B12 levels at the time of delivery. ${ }^{3}$ Pancytopenia is associated with many maternal and foetal complications during pregnancy like maternal sepsis, postpartum haemorrhage, pre-eclampsia and preterm labour, IUGR and intrauterine foetal demise.

\section{METHODS}

The objective of this study was to know the incidence of pancytopenia in pregnancy and to know the effect on Feto-maternal outcome. The study was conducted at BLDE (Deemed to be) University, Shri B. M. Patil Medical College Hospital and Research Centre. It's an observational study done from November 2019 to April 2020 . 


\section{Inclusion criteria}

- All pregnant women diagnosed with pancytopenia at admission.

\section{Exclusion criteria}

- Twin pregnancies

- Patient on treatment with any drugs which may lead pancytopenia.

The participants enrolled in the study were subjected for further clinical and laboratory evaluation and followed for feto-maternal outcome.

\section{Statistical analysis}

All characteristics were summarized descriptively. For continuous variables, the summary statistics of mean \pm standard deviation (SD) were used. For categorical data, the number and percentage were used in the data summaries and diagrammatic presentation. Data were analysed using SPSS software v.23.0 and Microsoft office 2007.

\section{RESULTS}

In this study the total number of patients admitted to labour room were 1230 , of which 38 cases were diagnosed with pancytopenia. The incidence of in this study is $3 \%$. The mean age of the participants was 24.9 years (22-28 years) with $\mathrm{SD} \pm 2.2$. In this study 26 participants were multigravida $(68.4 \%)$ and 12 were primigravida $(31.6 \%)$. Maximum participants were in the age group of 20 to 25 years $(55.3 \%)$ Table 1.

Table 1: Age distribution.

\begin{tabular}{|ll|l|}
\hline Age (years) & $\mathbf{N}$ & Percentage \\
\hline$<20$ & 2 & $5.3 \%$ \\
\hline $20-25$ & 21 & $55.3 \%$ \\
\hline $25-30$ & 15 & $39.5 \%$ \\
\hline Total & 38 & $100.0 \%$ \\
\hline
\end{tabular}

Table 2: Gestational age distribution.

\begin{tabular}{|ll|l|}
\hline GA (weeks) & $\mathbf{N}$ & Percentage \\
\hline $28-32$ & 10 & $26.3 \%$ \\
\hline $32-36$ & 9 & $23.7 \%$ \\
\hline $36-40$ & 19 & $50.0 \%$ \\
\hline Total & 38 & $100.0 \%$ \\
\hline
\end{tabular}

Most of the patients presented as term gestation $(50 \%)$ Table 2. The mean levels of $\mathrm{HB}, \mathrm{WBC}$ and platelet counts was 5.6 gm\%, 3434.7/cumm, and 39236.8/ cumm respectively (Table 3 ). The most common presenting complaint was pregnancy induced hypertension $(52.6 \%)$ (Table 4). PPH was the most commonly encountered postpartum complication in the participants $(39.5 \%)$ and others as mentioned in the (Table 5). Out of the 38 babies born early onset sepsis and LBW was seen as most common complication (26.3\% each) followed by IUD (Table 6).

Table 3: Haematological parameters.

\begin{tabular}{|llll|}
\hline Descriptive statistics of haematological parameters & Range & Mean & SD \\
\hline Haemoglobin $(\mathrm{gm} / \mathrm{dl})$ & $2.1-7.1$ & 5.6 & 1.5 \\
\hline Platelet count & $20000-60000$ & 39236.8 & 13621.2 \\
\hline White blood cell count & $2020-4170$ & 3434.7 & 746.7 \\
\hline
\end{tabular}

Table 4: Antenatal complications.

\begin{tabular}{|lll|}
\hline Complaints at presentation & $\mathbf{N}$ & Percentage \\
\hline Fever & 6 & $15.8 \%$ \\
\hline Giddiness & 2 & $5.3 \%$ \\
\hline Labour pain & 2 & $5.3 \%$ \\
\hline Leak PV & 2 & $5.3 \%$ \\
\hline PIH & 20 & $52.6 \%$ \\
\hline PIH with HELLP syndrome & 6 & $15.8 \%$ \\
\hline Total & 38 & $100.0 \%$ \\
\hline
\end{tabular}

All the participants enrolled in the study were vegetarian in diet and had protein calorie deficiency and on laboratory evaluation had low levels of vitamin B12 $(153.3 \pm 9.1 \mathrm{pg} / \mathrm{dl})$ and folic acid levels $(2.5 \pm 0.7 \mathrm{ng} / \mathrm{dl})$.
Table 5: Postpartum complications.

\begin{tabular}{|lll|}
\hline Maternal complications & $\mathbf{N}$ & Percentage \\
\hline Hematemesis & 1 & $2.6 \%$ \\
\hline Fever & 8 & $21.1 \%$ \\
\hline PPH & 15 & $39.5 \%$ \\
\hline Puerperal sepsis & 5 & $13.2 \%$ \\
\hline Uneventful & 9 & $23.7 \%$ \\
\hline Total & 38 & $100.0 \%$ \\
\hline
\end{tabular}

All the 38 patients had peripheral smear study showing pancytopenic picture. Mean vitamin B12 levels of this study patients was $150.5 \mathrm{pg} / \mathrm{ml}$ (normal range 195-950 $\mathrm{pg} / \mathrm{ml})$. Mean folate levels of this patients was 2.725 $\mathrm{ng} / \mathrm{ml}$ (normal range 2-20 $\mathrm{ng} / \mathrm{ml}$ ). 
Table 6: Foetal complications.

\begin{tabular}{|lll|}
\hline Neonatal complications & $\mathbf{N}$ & Percentage \\
\hline Early onset sepsis & 10 & $26.3 \%$ \\
\hline IUD & 4 & $10.5 \%$ \\
\hline LBW & 10 & $26.3 \%$ \\
\hline Nil & 14 & $36.8 \%$ \\
\hline Total & 38 & $100.0 \%$ \\
\hline
\end{tabular}

\section{DISCUSSION}

Anaemia during pregnancy is a public health problem especially in developing countries and is associated with adverse pregnancy outcomes4.Globally $56 \%$ of pregnant women in low- and middle-income countries have anaemia. The prevalence of anaemia is highest among pregnant women in Sub-Saharan Africa (57\%) followed by pregnant women in South East Asia (48\%). ${ }^{5}$

The causes of anaemia are multifactorial in which micronutrient deficiencies like iron and vitamin B12 plays an important role. Anaemia during pregnancy varies due to geographical location, dietary practice and season. Pancytopenia is a clinical phenomenon characterized by the reduction in all three major elements of blood.

Pancytopenia may go undetected initially due to mild impairment in the bone marrow and may become apparent only during times of stress or during increased demand, (e.g. pregnancy, bleeding, infection). ${ }^{6}$ Bone marrow failure syndromes and malignancies are important causes for pancytopenia and non-malignant conditions like infections (HIV, EBV, tuberculosis) and nutritional anaemia (severe vitamin B12 and folate deficiency) are also the major causes. ${ }^{7}$

A systematic review and meta-analysis of individual participant data in associations of maternal vitamin B12 concentrations in pregnancy with the risks of preterm birth and low birth weight conducted by Rognen $\mathrm{T}$ et al observed that vitamin B12 deficiency in pregnancy was associated with higher risk of preterm birth. A study by Pawlak $\mathrm{N}$ et al, shows that there is a high prevalence of vitamin B12 deficiency among pregnant vegetarians. ${ }^{8}$ Low maternal serum concentration of vitamin B 12 during the first trimester is a risk factor for NTD and poor maternal outcomes such as pre-eclampsia and neurological impairment. Govindappagari $S$ et al, reported a case of severe vitamin B12 deficiency in pregnancy mimicking HELLP syndrome and emphasized the importance of screening for vitamin B12 deficiency in pregnancy.

A study done by Koebnick $\mathrm{C}$ et al showed that the prevalence of B12 deficiency increased between second and third trimester from $8-35 \%$. Van de Velde $\mathrm{N}$ et al concluded that severe pancytopenia caused but ineffective hematopoiesis because of folate and vitamin
B12 deficiency. Rajput Y et al, concluded that association of pancytopenia with pregnancy is rare entity with increased risk of poor maternal and fetal outcome. ${ }^{9}$

In this study, the incidence of pancytopenia with pregnancy was very low as stated by other authors (3\%) and were associated with maternal complications like PIH, HELLP syndrome, puerperal sepsis, PPH and fetal like neonatal sepsis, low birth weight and intrauterine death. This study showed that diet of all the participants was vegetarian with vitamin B12 and folic acid deficiency. The participants were not subjected to Bone marrow study as the cause of pancytopenia was diagnosed with blood investigations and dietary history.

\section{CONCLUSION}

Association of pancytopenia with pregnancy is a rare entity yet it has increased risk of poor maternal and foetal outcome. Early diagnosis and intervention bring favourable maternal and foetal outcome. This study observed that all the participants were vegetarian by diet along with Vit-B12 and folate deficiency leading to pancytopenia. Hence, proper dietary counselling and well-balanced dietary plans even with plant originate food can prevent the micronutrients deficiency and avoid the deleterious consequences like pancytopenia. There are no many studies on pregnancy with pancytopenia. Hence, further larger studies are required.

\section{ACKNOWLEDGMENTS}

Authors would like to thank all the staff members of department of obstetrics and gynecology, of BLDE (DU) Shri B. M. Patil Medical College for their support and guidance and Dr. Shanawaz assistant professor from department of community medicine for statistical analysis.

\section{Funding: No funding sources}

Conflict of interest: None declared

Ethical approval: The study was approved by the Institutional Ethics Committee

\section{REFERENCES}

1. Metikurke SH, Bhavika R. Correlation of bone marrow aspirate, biopsies and touch imprint findings in pancytopenia. J Hematol. 2013;2(1):8-13.

2. Varma N, Dash S. A reappraisal of underlying pathology in adult patients presenting with pancytopenia. Trop Geograph Med. 1992;44(4):3227.

3. Visentin CE, Masih SP, Plumptre L, Schroder TH, Sohn KJ, Ly A, et al. Low serum vitamin B-12 concentrations are prevalent in a cohort of pregnant Canadian women. The J Nutrit. 2016;146(5):103542. 
4. Breymann C. Iron deficiency and anaemia in pregnancy: modern aspects of diagnosis and therapy. Eur J Obstet Gynecol Reprod Biol. 2005;123:S3-13.

5. World Health Organization. Worldwide prevalence of anaemia 1993-2005: WHO global database on anaemia, 2008. Available at: https://www.who.int/nutrition/publications/micronutr ients/anaemia_iron_deficiency/9789241596657/en/. Accessed on $12^{\text {th }}$ April 2020.

6. Shimamura A, Alter BP. Inherited aplastic anaemia syndromes. In Wintrobe's Clinical Hematology: Thirteenth Edition; Wolters Kluwer Health Adis (ESP); 2013:954-964.

7. Imbert M, Scoazec JY, Mary JY, Jouzult H, Rochant $\mathrm{H}$, Sultan C. Adult patients presenting with pancytopenia: a reappraisal of underlying pathology and diagnostic procedures in 213 cases. Hematol Pathol. 1989;3(4):159-67.

8. Pawlak R, Parrott SJ, Raj S, Cullum-Dugan D, Lucus D. How prevalent is vitamin B12 deficiency among vegetarians?. Nutrit Rev. 2013;71(2):110-7.

9. Rajput Y, Wankhede UN. A rare case report: pregnancy with pancytopenia. Int $\mathbf{J}$ Reprod Contracept Obstet Gynecol. 2017;6(12):5633-5.

Cite this article as: Mathapati S, Biradar A, Sangolli L, Gamini BS, Sridevi HS. Pregnancy with pancytopenia: an observational study. Int J Reprod Contracept Obstet Gynecol 2020;9:3134-7. 